\title{
Clinical outcomes in patients with cancer of unknown primary site treated by gastrointestinal oncologists
}

\author{
Sakiko Yamane ${ }^{1}$, Chikatoshi Katada ${ }^{1}$, Satoshi Tanabe ${ }^{2}$, Mizutomo Azuma1, \\ Kenji Ishido ${ }^{1}$, Takafumi Yano ${ }^{1}$, Takuya Wada ${ }^{1}$, Akinori Watanabe ${ }^{1}$, \\ Natsuko Kawanishi ${ }^{1}$, Yasuaki Furue ${ }^{1}$, Yuki Kondo ${ }^{1}$, Shouko Komori ${ }^{3}$, \\ Hiromichi Ishiyama $^{3}$, Kazushige Hayakawa ${ }^{3}$, Wasaburo Koizumi ${ }^{1}$ \\ 'Department of Gastroenterology, Kitasato University School of Medicine, Sagamihara, Japan; \\ ${ }^{2}$ Department of Research and Development Center for New Medical Frontiers, Kitasato University School \\ of Medicine, Sagamihara, Japan; \\ ${ }^{3}$ Department of Radiology and Radiation Oncology, Kitasato University School of Medicine, Sagamihara, Japan
}

\section{ABSTRACT}

Objective: To evaluate the clinical outcomes in patients with cancer of an unknown primary site (CUP), who were treated by gastrointestinal oncologists. Methods: We retrospectively studied 29 patients with CUP who were presented at the Department of Gastroenterology, Kitasato University Hospital from October 2005 to October 2013, and were treated by the gastrointestinal oncologists. The patients were divided into two groups, namely chemotherapy group and symptomatic therapy group, and the clinical characteristics and survival times were compared. The clinical course was studied according to the histologic type (adenocarcinoma or non-adenocarcinoma), prognostic subset (favorable or unfavorable), and the presence or absence of chemotherapy. Results: The chemotherapy group comprised 19 patients, and the symptomatic therapy group comprised 10 patients. The median survival time was 11 months in the chemotherapy group and 3 months in the symptomatic therapy group. Twentytwo patients had adenocarcinoma, and 7 had non-adenocarcinoma. Of the 22 patients with adenocarcinoma, 2 belonged to the favorable prognostic subset and received chemotherapy. One of these patients died of cancer at 47 months, and the other was alive and disease free at 58 months. Among the 20 patients with adenocarcinoma in the unfavorable prognostic subset, 16 received chemotherapy and had a median survival of 16 months. Seven $(44 \%)$ of these patients survived for at least 21 months, and 3 patients who could receive 3 or more regimens survived for at least 46 months. Conclusion: It might be appropriate for gastrointestinal oncologists to treat CUP on the basis of clinical experience, depending on the situation.

Address for Correspondence: Dr. Chikatoshi Katada, M.D., Ph.D. Department of Gastroenterology, Kitasato University School of Medicine, 1-15-1 Kitasato, Minami, Sagamihara, Kanagawa252-0374, Japan. Email: ckatada@med.kitasato-u.ac.jp

\begin{tabular}{|c|}
\hline Access this article online \\
\hline $\begin{array}{l}\text { Website: } \\
\text { www.intern-med.com }\end{array}$ \\
\hline $\begin{array}{l}\text { DOI: } \\
\text { 10.1515/jtim-2017-0006 }\end{array}$ \\
\hline Quick Response Code: \\
\hline 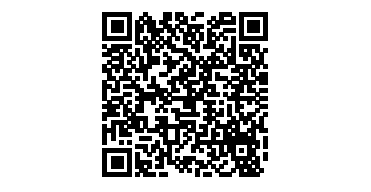 \\
\hline
\end{tabular}

Key words: cancer of an unknown primary site, adenocarcinoma, favorable subset, unfavorable subset, gastrointestinal oncologist, chemotherapy

\section{INTRODUCTION}

Cancer of an unknown primary site (CUP) is defined as a histologically confirmed metastatic malignant tumor for which no primary lesion can be identified during pretreatment evaluations. ${ }^{[1,2]}$ Outcomes are extremely poor, with a median survival of 3 to 9 months. ${ }^{[3-7]}$ CUP can be divided into 2 groups according to symptoms and clinical features: a good outcome group and a poor outcome group. ${ }^{[8]}$ Chemotherapy regimens recommendable as standard treatment have yet to be established for patients with CUP, associated with poor prognostic clinical features. ${ }^{[9]}$ CUP has various histologic types and tumor locations. If the main symptoms and primary lesions involve the abdomen, gastrointestinal oncologists often perform treatment on the basis of clinical experience. We retrospectively studied the clinical results of treatment performed by the gastrointestinal oncologists for CUP to evaluate whether it is appropriate for gastrointestinal oncologists to treat such patients under certain conditions. 


\section{MATERIALS AND METHODS}

We retrospectively studied 29 patients who were presented at the Department of Gastroenterology, Kitasato University Hospital from October 2005 through October 2013 and satisfied the following inclusion criteria: 1) CUP was diagnosed on extensive examinations; 2) a malignant tumor was definitively diagnosed based on the histopathological examination of metastatic lesions; and 3) gastrointestinal oncologists administered treatment on the basis of clinical experience.

The study variables were as follows: 1) major symptoms and methods used for definitive histopathological diagnosis, 2) patient characteristics and survival times in patients who were given chemotherapy (chemotherapy group) and those given symptomatic therapy (symptomatic therapy group), and 3) the clinical course according to histologic type (adenocarcinoma or non-adenocarcinoma), prognostic subset (favorable or unfavorable), and the presence or absence of chemotherapy.

In our study, the favorable prognostic subset was defined as patients with following conditions: ${ }^{[8]} 1$ ) adenocarcinoma: women with isolated lymphadenopathy, women with peritoneal carcinomatosis, men with blastic bone metastasis or elevated serum prostate-specific antigen (PSA) with a single metastatic site; 2) squamous carcinoma: cervical lymphadenopathy, inguinal lymphadenopathy; 3) poorly differentiated carcinoma: young men with a mediastinal or retroperitoneal mass (or both); all others with good performance status.

The tumor site was classified into 8 regions: cerebrospinal region, cervical region, thoracic region, intra-abdominal region, retroperitoneal region, bone, bone marrow, and skin.

\section{RESULTS}

The major symptoms were as follows: abdominal symptoms in 12 patients, no symptoms in 7 (abnormality was found on medical checkups), a palpable mass in 4 , neurologic symptoms in 3, skin symptoms in 2, and thoracic symptoms in 1. The method used for definitive histopathological diagnosis was biopsy in 24 patients and cytological examination in 5 . The biopsy sites were as follows: lymph nodes in 10 patients (cervical in 3, intra-abdominal in 3, supraclavicular in 2, axillary in 1, and inguinal in 1), the gastrointestinal tract in 4 , the liver in 3 , an abdominal mass in 3, bone in 2, and skin in 2. Specimens for cytological examination were obtained from ascites in 4 patients and cerebrospinal fluid in 1 .

Table 1 shows the patient characteristics and survival times in the chemotherapy group and the symptomatic therapy group. The median follow-up was 7 months (range: 2 to
100). The chemotherapy group comprised 19 patients (8 men and 11 women), and the symptomatic therapy group comprised of 10 patients ( 8 men and 2 women). The median age was 60 years (range: 46 to 81 years) and 73 years (range: 65 to 76 years), respectively. The Eastern Cooperative Oncology Group performance status was 0 to 1 in 5 patients and 2 to 4 in 14 patients in the chemotherapy group, and 0 to 1 in 3 patients and 2 to 4 in 7 patients in the symptomatic therapy group. The histologic type was adenocarcinoma in 18 patients and small-cell carcinoma in 1 patient in the chemotherapy group, and adenocarcinoma in 4 patients, squamous-cell carcinoma in 2 patients, malignant melanoma in 1 patient, small-cell carcinoma in 1 patient, and unclassifiable in 2 patients in the symptomatic therapy group. The prognostic subset was favorable in 2 patients and unfavorable in 17 patients in the chemotherapy group and was unfavorable in all 10 patients in the symptomatic therapy group. The number of tumor sites was 1 in 8 patients, 2 in 3 patients, 3 in 5 patients, 4 in 2 patients, and 5 in 1 patient in the chemotherapy group and 1 in 0 patients, 2 in 5 patients, 3 in 2 patients, 4 in 1 patient, and 5 in 2 patients in the symptomatic therapy group. The median survival was 11 months (range: 4 to 100 ) in the chemotherapy group and 3 months (range: 2 to 7 ) in the symptomatic therapy group.

Figure 1 shows the survival times according to the histologic type (adenocarcinoma or non-adenocarcinoma), prognostic subset (favorable or unfavorable), and the presence or absence of chemotherapy. Overall, 22 patients had adenocarcinoma, and 7 had non-adenocarcinoma. Of the 22 patients with adenocarcinoma, 2 belonged to the favorable prognostic subset, and both received chemotherapy. One of these patients died of adenocarcinoma at 47 months, and the other was alive without disease at 58 months. The other 20 patients with adenocarcinoma belonged to the unfavorable prognostic subset. Sixteen of these patients received chemotherapy and had a median survival of 16 months (range: 4 to 100). The other 4 patients with adenocarcinoma did not receive chemotherapy and had a median survival of 4 months (range: 3 to 4 ). All 7 patients with non-adenocarcinoma belonged to the unfavorable subset. One of these patients received chemotherapy and was alive with disease at 10 months. The other 6 patients with non-adenocarcinoma did not receive chemotherapy and had a median survival of 3 months (range: 2 to 7 ).

Table 2 summarizes the sites of the primary lesions, the number of lesion sites, the administered chemotherapy regimens, survival times, and outcomes in the 16 patients with adenocarcinoma who belonged to the unfavorable prognostic subset and received chemotherapy. Gastrointestinal oncologists selected the chemotherapy regimens on the basis of their clinical experience. Seven 
Yamane et al.: Treatment for cancer of unknown primary site

\begin{tabular}{|c|c|c|}
\hline & $\begin{array}{l}\text { Chemotherapy group } \\
n=19\end{array}$ & $\begin{array}{l}\text { Symptomatic therapy group } \\
n=10\end{array}$ \\
\hline \multicolumn{3}{|l|}{ Patient characteristics } \\
\hline \multicolumn{3}{|l|}{ Age (years) } \\
\hline Median & 60 & 73 \\
\hline Range & $46-81$ & $65-76$ \\
\hline \multicolumn{3}{|l|}{ Gender } \\
\hline Male/female & $8 / 11$ & $8 / 2$ \\
\hline \multicolumn{3}{|l|}{ Performance status } \\
\hline $0-1 / 2-4$ & $5 / 14$ & $3 / 7$ \\
\hline \multicolumn{3}{|l|}{ Histologic type } \\
\hline Adenocarcinoma & 18 & 4 \\
\hline Squamous-cell carcinoma & 0 & 2 \\
\hline Malignant melanoma & 0 & 1 \\
\hline Small-cell carcinoma & 1 & 1 \\
\hline Unclassifiable carcinoma & 0 & 2 \\
\hline \multicolumn{3}{|l|}{ Prognostic Subsets } \\
\hline Favorable & 2 & 0 \\
\hline Unfavorable & 17 & 10 \\
\hline \multicolumn{3}{|l|}{ No. of tumor locations* } \\
\hline 1 region & 8 & 0 \\
\hline 2 regions & 3 & 5 \\
\hline 3 regions & 5 & 2 \\
\hline 4 regions & 2 & 1 \\
\hline 5 regions & 1 & 2 \\
\hline \multicolumn{3}{|l|}{ Survival time (months) ${ }^{* *}$} \\
\hline Median & 11 & 3 \\
\hline Range & $4-100$ & $2-7$ \\
\hline
\end{tabular}

* Regions: cerebrospinal, cervical, thoracic, intra-abdominal, retroperitoneal, bone, bone marrow, and skin; ** Median follow-up period: 7 months (range, 2 to 100$)$

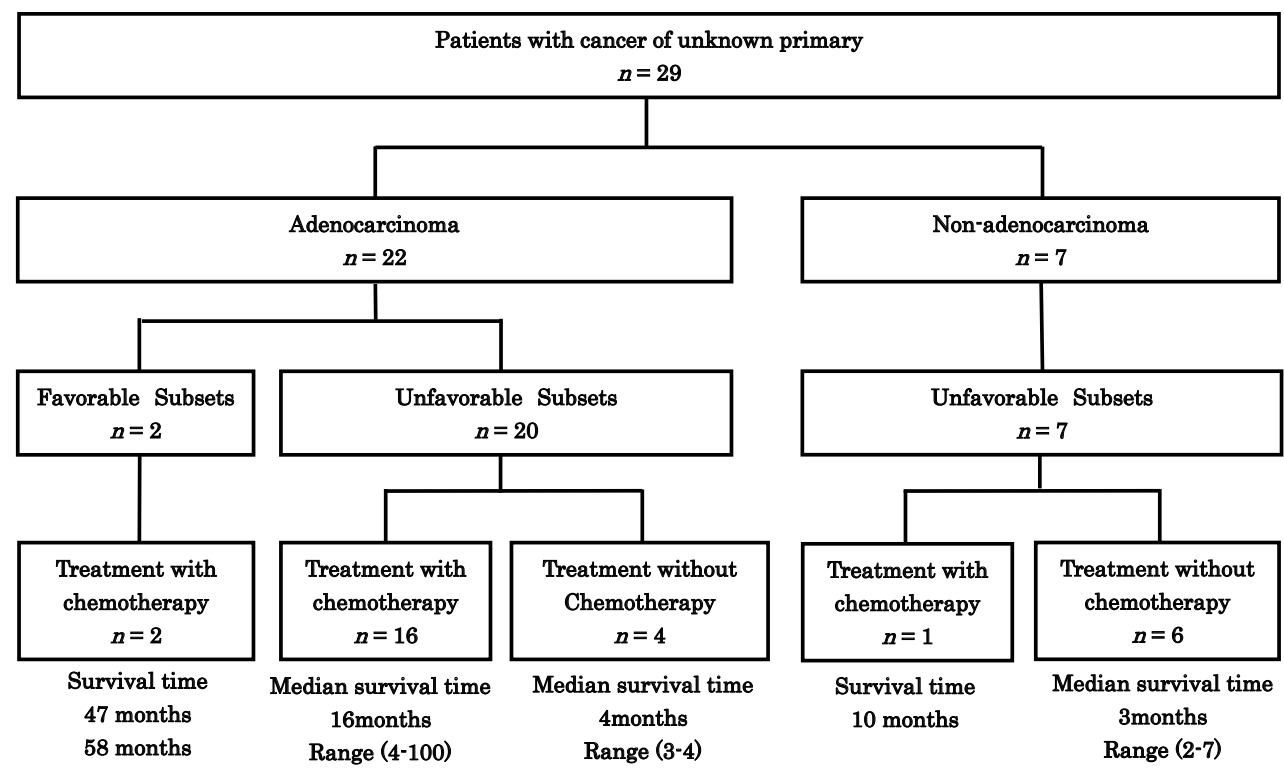

Figure 1: Survival time according to histologic type, prognostic subset, and the presence or absence of chemotherapy 
Yamane et al: : Treatment for cancer of unknown primary site

\begin{tabular}{|c|c|c|c|c|c|c|c|c|}
\hline Case & Main lesion & $\begin{array}{l}\text { No. of } \\
\text { regions }\end{array}$ & $\begin{array}{l}\text { 1st } \\
\text { line }\end{array}$ & $\begin{array}{l}\text { 2nd } \\
\text { line }\end{array}$ & $\begin{array}{l}\text { 3rd } \\
\text { line }\end{array}$ & $\begin{array}{l}\text { 4th } \\
\text { line }\end{array}$ & $\begin{array}{l}\text { Survival } \\
\text { time } \\
\text { (months) }\end{array}$ & Outcome \\
\hline 1 & Peritoneal dissemination & 2 & $\mathrm{~S} 1+\mathrm{CDDP}$ & $\mathrm{S} 1+\mathrm{DTX}$ & CPT & $\mathrm{MTX}+5 \mathrm{FU}$ & 100 & Dead \\
\hline 2 & Hilar tumor & 1 & FP-R & S1 & CPT & & 60 & Alive \\
\hline 3 & Duodenal tumor & 1 & S1 & GEM & $\mathrm{GEM}+\mathrm{S} 1$ & & 46 & Dead \\
\hline 4 & Abdominal subcutaneous mass & 1 & $\mathrm{~S} 1+\mathrm{DTX}$ & PTX & & & 30 & Dead \\
\hline 5 & Inguinal lymph nodes & 2 & S1 & & & & 25 & Dead \\
\hline 6 & Cervical lymph nodes & 4 & $\mathrm{~S} 1+\mathrm{CDDP}$ & СРТ & & & 22 & Dead \\
\hline 7 & Hepatic tumor & 3 & XELOX + Bv & $\mathrm{S} 1+\mathrm{CPT}$ & & & 21 & Dead \\
\hline 8 & Bone, bone marrow & 4 & $\mathrm{MTX}+5 \mathrm{FU}$ & PTX & & & 11 & Dead \\
\hline 9 & Hepatic tumor & 3 & GEM + CDDP & & & & 11 & Alive \\
\hline 10 & Ascites & 2 & $\mathrm{PTX}+\mathrm{CBDCA}$ & S1 & & & 9 & Dead \\
\hline 11 & Gluteal mass & 4 & $\mathrm{~S} 1+\mathrm{CDDP}$ & S1 & & & 9 & Dead \\
\hline 12 & Meninges & 3 & Intraspinal injection of MTX & СРТ & & & 7 & Alive \\
\hline 13 & Intra-abdominal lymph nodes & 3 & $\mathrm{~S} 1+\mathrm{CDDP}$ & & & & 7 & Dead \\
\hline 14 & Colon & 1 & PTX + CBDCA & & & & 7 & Dead \\
\hline 15 & Intra-abdominal lymph nodes & 2 & $\mathrm{~S} 1+\mathrm{CDDP}$ & & & & 5 & Dead \\
\hline 16 & Ascites & 4 & $\mathrm{~S} 1+\mathrm{DTX}$ & & & & 4 & Alive \\
\hline
\end{tabular}

CDDP: cisplatin; CPT: irinotecan; MTX: methotrexate; 5-FU: 5-fluorouracil; FP-R: 5-fluorouracil, cisplatin, and radiotherapy; GEM: gemcitabine; DTX: docetaxel; PTX: paclitaxel; XELOX: capecitabine and oxaliplatin; CBDCA: carboplatin.

(44\%) of the 16 patients survived for 21 months or longer, and 3 patients who received 3 or more regimens survived for 46 months or longer.

\section{DISCUSSION}

The median survival time in 19 patients with CUP who received chemotherapy prescribed by gastrointestinal oncologists in our hospital was 11 months (range: 4 to 100). Although there was selection bias in focusing on patients who could receive chemotherapy, the treatment outcomes were good, given that 17 of the 19 patients who received chemotherapy belonged to the unfavorable prognostic subset. Moreover, the survival times in the 3 patients with adenocarcinoma who belonged to the unfavorable prognostic subset and received 3 or more chemotherapy regimens were 100,60 , and 46 months, respectively, indicating a prolonged survival.

The patient who survived for 100 months had CUP with peritoneal dissemination and multiple intraabdominal lymph-node metastases. Poorly differentiated adenocarcinoma was histopathologically diagnosed on biopsy of disseminated lesions. The first-line treatment was 5 courses of S-1 plus cisplatin. The second-line treatment was 50 courses of S-1 plus docetaxel. The third-line treatment was 7 courses of irinotecan, and the fourth-line treatment was 76 courses of methotrexate plus 5-fluorouracil.

The patient who survived for 60 months had CUP with a solitary hilar lymph-node metastasis. Histologically, poorly differentiated adenocarcinoma was diagnosed on the biopsy of the metastatic lymph nodes. The first-line treatment was 6 courses of chemoradiotherapy with 5-fluorouracil plus cisplatin, the second-line treatment was 1 course of S-1, and the third-line treatment was 14 courses of irinotecan.

The patient with a survival time of 46 months had CUP with multiple retroperitoneal lymph-node metastases. Poorly differentiated adenocarcinoma was histologically diagnosed on cytologic examination of specimens of the metastatic lymph nodes obtained by endoscopic ultrasound-guided fine-needle aspiration. The first-line treatment was 28 courses of S-1, the second-line treatment was 9 courses of gemcitabine, and the third-line treatment was 6 courses of gemcitabine plus S-1.

In patients with adenocarcinoma who belong to the unfavorable prognostic subset, the indications for secondand third-line treatment should be carefully evaluated. ${ }^{[10-14]}$ However, our results suggested that treatment with 3 or 
more chemotherapy regimens might prolong survival in some patients. Treatment strategies should therefore be tailored to the needs of individual patients.

Phase III studies in patients with CUP have been performed since the 1980s. ${ }^{[15-17]}$ In the 1990s, anticancer agents effective against many types of cancer, such as paclitaxel, docetaxel, irinotecan, gemcitabine, and vinorelbine, were launched. Phase II studies evaluating these agents combined with a platinum compound, including clinical trials in patients with CUP, were successively performed and reported. ${ }^{[18-22]}$ Many of these studies obtained a response rate of about $30 \%$ and an overall survival of less than 10 months. ${ }^{[18,19]}$ In these studies, an overall survival of longer than 10 months was obtained in patients who received combined chemotherapy with a platinum preparation plus taxane. At present, this is the most commonly used regimen followed in patients with CUP who do not have a favorable prognosis. ${ }^{[23]}$

In our study, among 16 patients who received chemotherapy for adenocarcinoma with an unfavorable prognosis, $12(75 \%)$ received fluoropyrimidine derivatives, and $10(62.5 \%)$ received platinum preparations as first-line treatment, indicating high usage of these drugs. In contrast, the taxanes were given to only 4 patients $(25 \%)$. The combined treatment with a platinum preparation and a taxane was given to only 2 patients (12.5\%), indicating a low frequency of use. These patients survived for 7 months and 9 months, respectively. The median survival time in the 16 patients who received chemotherapy for adenocarcinoma and belonged to the unfavorable prognostic subset was 16 months. Our findings thus suggest that chemotherapy regimens selected by gastrointestinal oncologists on the basis of their clinical experience might contribute to better outcomes in patients with CUP.

Recently, treatment strategies have been developed on the basis of the characteristics of cancer, such as histologic type and gene expression. ${ }^{[24,25]}$ Progress in personalized medicine is expected to improve treatment outcomes. Our study was retrospective and was performed at a single hospital with a small number of patients who were treated by gastrointestinal oncologists. Because CUP is characterized by various histologic types and tumor locations, treatment strategies have yet to be standardized. However, good treatment outcomes were obtained in patients with CUP who were given chemotherapy by gastrointestinal oncologists. In conclusion, it might be appropriate for gastrointestinal oncologists to treat CUP on the basis of clinical experience, depending on the situation.

\section{Conflict of Interest}

The authors declare there is no conflict of interest.

\section{REFERENCES}

1. Greco FA, Hainsworth JD. Cancer of Unknown Primary Site. In: Devita, Hellman \& Rosenberg's Cancer: Principles \& Practice of Oncology. 8th ed. Philadelphia: Lippincott Williams \& Wilkins, 2008: 2363-87.

2. Greco FA, Hainsworth JD. Tumors of unknown origin.CA Cancer JClin 1992; 42:96-115.

3. Greco FA, Burris HA, Litchy S, Barton JH, Bradof JE, Richards P, et al. Gemcitabine, carboplatin, and paclitaxel for patients with carcinoma of unknown primary site: A Minnie Pearl Cancer Research Network study. J ClinOncol 2002; 15: 1651-6.

4. Pavlidis N, Briasoulis E, Hainsworth J, Greco FA. Diagnostic and therapeutic management of cancer of an unknown primary. Eur J Cancer 2003; 39: 1990-2005.

5. Hainsworth JD, Spigel DR, Farley C, Thompson DS, Shipley DL, Greco FA; Minnie Pearl Cancer Research Network. Phase II trial of bevacizumab and erlotinib in carcinomas of unknown primary site: the Minnie Pearl Cancer Research Network. J ClinOncol 2007; 25: 1747-52.

6. Schneider BJ, El-Rayes B, Muler JH, Philip PA, Kalemkerian GP, Griffith $\mathrm{KA}$, et al. Phase II trial of carboplatin, gemcitabine, and capecitabine in patients with carcinoma of unknown primary site. Cancer 2007; 110: $770-5$.

7. Pimiento JM, Teso D, Malkan A, Dudrick SJ, PalestyJA.Cancer of unknown primary origin: A decade of experience in a community-based hospital. Am J Surg 2007; 194: 833-8.

8. Hainsworth J D, Karim Fizazi. Treatment for Patients With Unknown Primary Cancer and Favorable Prognostic Factors. SeminOncol 2009; 36:44-51.

9. Amela EY, Lauridant-Philippin G, Cousin S, Ryckewaert T, Adenis A, Penel N.Management of "unfavourable" carcinoma of unknown primary site: synthesis of recent literature.Crit Rev OncolHematol2012; 84: 21323.

10. Culine S, Ychou M, Fabbro M, Romieu G, Cupissol D. 5-fluorouracil and leucovorin as second-line chemotherapy in carcinomas of unknown primary site. Anticancer Res 2001; 21:1455-7.

11. Hainsworth JD, Burris HA 3rd, Calvert SW, Willcutt NT, Scullin DC Jr, Bramham J, et al. Gemcitabine in the second-line therapy of patients with carcinoma of unknown primary site: a phaseII trial of the Minnie Pearl Cancer Research Network. Cancer Invest 2001;19: 335-9.

12. Hainsworth JD, Spigel DR, Raefsky EL, Kuzur ME, Yost K, Kommor M, et al. Combination chemotherapy with gemcitabine and irinotecan in patients with previously treated carcinoma of an unknown primary site:a Minnie Pearl Cancer Research Network PhaseII trial. Cancer 2005; 104: 1992-7.

13. Pouessel D, Culine S, Becht C, Romieu G, Fabbro M, Ychou M, et al. Gemcitabine and docetaxel after failure of cisplatin-based chemotherapy in patients with carcinoma of unknown primary site. Anticancer Res 2003; 23:2801-4.

14. Hainsworth JD, Spigel DR, Farley C, Thompson DS, Shipley DL, Greco FA; Minnie Pearl Cancer Research Network. PhaseII trial of bevacizumab and erlotinib in carcinomas of unknown primary site: the Minnie Pearl Cancer Research Network. J ClinOncol2007; 25: 1747-52.

15. Milliken ST, Tattersall MH, Woods RL, Coates AS, Levi JA, Fox RM, et al. Metastatic adenocarcinoma of unknown primary site. A randomized study of two combination chemotherapy regimens. Eur J Cancer ClinOncol 1987; 23: 1645-8.

16. Falkson CI, Cohen GL. Mitomycin C, epirubicin and cisplatin versus mitomycin $\mathrm{C}$ alone as therapy for carcinoma of unknown primary origin. Oncology 1998; 55: 116-21.

17. Eagan RT, Therneau TM, Rubin J, Long HJ, Schutt AJ. Lack of value for cisplatin added to mitomycin-doxorubicin combination chemotherapy for carcinoma of unknown primary site. A randomized trial. Am J ClinOncol 1987; 10: 82-5.

18. Hainsworth JD, Erland JB, Kalman LA, Schreeder MT, Greco FA. 
Carcinoma of unknown primary site: treatment with 1-hour paclitaxel, carboplatin, and extended-schedule etoposide. J ClinOncol 1997; 15: 2385-93.

19. Briasoulis E, Kalofonos H, Bafaloukos D, Samantas E, Fountzilas G, Xiros $\mathrm{N}$, et al. Carboplatin plus paclitaxel in unknown primary carcinoma:a phaseII Hellenic Cooperative Oncology Group Study. J ClinOncol 2000; 18: 3101-7.

20. Culine S, Lortholary A, Voigt JJ, Bugat R, Théodore C, Priou F, et al; Trial for the French Study Group on Carcinomas of Unknown Primary (GEFCAPI 01). Cisplatin in combination with either gemcitabine or irinotecan in carcinomas of unknown primary site: results of a randomized phaseII study-trial for the French Study Group on Carcinomas of Unknown Primary (GEFCAPI 01). J ClinOncol 2003; 21:3479-82.

21. Palmeri S, Lorusso V, Palmeri L, Vaglica M, Porta C, Nortilli R, et al; Carcinomas of Unknown Primary Italian Study Group. Cisplatin and gemcitabine with either vinorelbine or paclitaxel in the treatment of carcinomas of unknown primary site : results of an Italian multicenter, randomized, phaseII study. Cancer 2006; 107: 2898-905.
22. Yonemori K, Ando M, Yunokawa M, Hirata T, Kouno T, Shimizu C, et al. Irinotecan plus carboplatin for patients with carcinoma of unknown primary site. Br J Cancer 2009; 100: 50-5.

23. Huebner G, Link H, Kohne CH, Stahl M, Kretzschmar A, Steinbach S, et al; German CUP Study Group. Paclitaxel and carboplatin vs gemcitabine and vinorelbine in patients with adeno-or undifferentiated carcinoma of unknown primary: a randomised prospective phaseII trial. Br J Cancer 2009; 100: 44-9.

24. Kurahashi I, Fujita Y, Arao T, Kurata T, Koh Y, Sakai K, et al. A Microarray-Based Gene Expression Analysis to Identify Diagnostic Biomarkers for Unknown Primary Cancer. Plos One 2013; 8:e63249.

25. Varadhachary GR, Raber MN, Matamoros A, Abbruzzese JL. Carcinoma of unknown primary with a colon-cancer profile-changing paradigm and emerging definitions. Lancet Oncol2008; 9: 596-9.

How to cite this article: Yamane S, Katada C, Tanabe S, Azuma M, Ishido $\mathrm{K}$, Yano $\mathrm{T}$, et al. Clinical outcomes in patients with cancer of unknown primary site treated by gastrointestinal oncologists. J Transl Intern Med 2017; 5: 58-63. 